\title{
What is 'good' mentoring? Understanding mentoring practices of teacher induction through case studies of Finland and Australia
}

Matti Pennanen $^{\mathrm{a} *, 1}$, Laurette Bristol $^{\mathrm{b}}$, Jane Wilkinson $^{\mathrm{c}}(\mathrm{D})$ and Hannu L.T. Heikkinen ${ }^{a}$

${ }^{a}$ Finnish Institute for Educational Research, University of Jyväskylä, P.O. Box 35, FI-40014 Jyväskylä, Finland; ${ }^{b}$ Education Department, Catholic College of Mandeville, Williamsfield P.O. Manchester, Jamaica, West Indies; ${ }^{c}$ Faculty of Education, Monash University, Wellington Road, Melbourne, Victoria, Australia

\begin{abstract}
Mentoring is a practice widely utilised to support new teachers. However, in locally formed systems, the practice of mentoring is conditioned by traditions and arrangements specific to the site. To understand 'good' mentoring, these local arrangements cannot be ignored. In this article, the theory of practice architectures is employed to make explicit the prefiguring arrangements of mentoring practices in Finland and NSW Australia. The findings suggest that mentoring practices are shaped by their ontological specificity and this makes reproducing mentoring practices in different sites problematic. Explicating the prefiguring architectures of practices is critical to understanding the contested nature of mentoring.
\end{abstract}

Keywords: mentoring; teacher induction; new teachers; social practice; practice theory

\section{Introduction}

The need to support the professional development of new teachers is a pressing challenge for education systems in many countries (Long 2009; Huizing 2012; Kane and Francis 2013). In the research literature, the topic is often examined through a variety of lenses, such as 'mentoring' of newly qualified teachers or 'teacher induction'. Mentoring has become the most popular form of teacher induction and this has influenced the synonymous use of mentoring and induction (Ingersoll and Smith 2004). However, the loose utilisation of these terms in the literature suggests a conceptual confusion about their employment. Hence, mentoring has been described as 'a

\footnotetext{
*Corresponding author. Email: matti.a.pennanen@jyu.fi

${ }^{1}$ Research was conducted in collaboration with Finnish Institute for Educational Research, University of Jyväskylä and Research Institute for Professional Practice, Learning and Education, Charles Sturt University.
} 
practice, which is ill-defined, poorly conceptualised and weakly theorised' (Colley 2003, 13; Bozeman and Feeney 2007).

The above are serious criticisms which this article attempts to address by conceptualising and theorising mentoring ontologically as a social practice, a '[...] coherent and complex form of socially established co-operative human activity' (MacIntyre 2007, 187) which is constituted '[...]in historical and social context[s] that give ... structure and meaning to what people do' (Wenger 1998, 47). The notion of mentoring as anchored within and prefigured by the specific contexts or sites (c.f. Schatzki's notion of site ontologies, 2003) adds to a growing literature theorising mentoring as social practice (Aspfors 2012; Kemmis et al. 2012; Kemmis and Heikkinen 2012; Kemmis, Heikkinen, et al. 2014).

In this article, we examine how particular kinds of practice arrangements or practice architectures (Kemmis and Grootenboer 2008) prefigure distinctively different purposes, understandings and manifestations of 'good mentoring' practice in a Finnish and New South Wales (NSW), Australian education site, respectively. We have chosen these two locales for comparison and contrast, as they illustrate the very different purposes which underline mentoring practices. For instance, formal mentoring of NSW beginning teachers forms one response to high levels of new teacher attrition (a deficit view of new teachers) compared to Finland with high levels of new teacher retention, where mentoring is viewed as an ongoing enrichment process for beginning and experienced teachers alike (an asset view of new teachers). We posit that the cultural, semantic, material and political differences in educational systems and national settings such as NSW, Australia and Finland create these different purposes for and understandings of mentoring. Consequently, they create differing mentoring practices. To understand the differences and similarities of mentoring practices between these two different sites and how this process occurs, we employ new insights in the field of practice theory (c.f. Kemmis, Wilkinson, et al. 2014; Wilkinson and Kemmis 2015).

The primary aim of our paper is to demonstrate how attention to the arrangements of practices and the distinctiveness of differing sites can contribute to richer theorisations of mentoring and in turn, advance both scholarship and practice in the field. A secondary aim is methodological. We have devoted a significant amount of time in the article to an articulation of our analytical processes, given the 'underdone' nature of much qualitative analysis in favour of an explication of the findings. This attention to methodology is an attempt to complement and add to our primary research aim, of more richly theorising mentoring as a social practice.

In the remainder of the article, we sketch the literature on mentoring, focusing on the varying conceptualisations and approaches to mentoring research and concluding with our key research questions. Next, we describe the two research settings and explicate our methodological approach. We 
then examine empirical data derived from case studies of peer-group mentoring (PGM) practice conducted in a Finnish education district, and a case study of more traditional, dyadic mentoring practices conducted in a small rural high school in NSW, Australia. We conclude with a discussion of the implications of these studies for mentoring theory and practice.

\section{Considerations of 'what is mentoring?'}

Before answering the question 'what is good mentoring?', it is crucial to know what mentoring is about. Mentoring has been studied in several academic fields, all of which have contributed to different understandings of the term. Hence, in order to investigate the practices of 'good mentoring', we need to understand the contested nature of mentoring and the conceptual differences underpinning its practices.

One way to answer the question of 'what is mentoring' is to examine the etymology of the word. The modern word mentor comes from the Fénelon's Les Aventures de Télémaque (Roberts 2000), where the character Mentor is

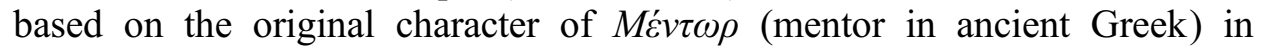
Homer's Odyssey. In the story of Odyssey, the goddess Athena appears in the likeness of Mentor to guide and advise Odysseus' son Telemachus to find his father. According to the Oxford English Dictionary, these two stories have shaped the meaning and definition of mentor, which generally means a person who acts as a guide or advisor for a younger and less experienced person. In the Odyssey, Mentor seems to possess divine knowledge and superior wisdom; also, in Fénelon's story, Mentor's role as a counsellor is emphasised. Contemporarily, the word mentor has gained multiple meanings: a person who offers support and guidance to another; an experienced and trusted counsellor; or a patron, a sponsor (Oxford University Press n.d.).

The etymology for the word mentor actually goes beyond the ancient Greek. It is suggested that the word mentor is an agent noun of mentos (intent, purpose, spirit and passion) descended from the ProtoIndo-European word mon-eyo- (c.f. Sanskrit man-tar- 'one who thinks' and Latin mon-i-tor, 'one who admonishes') and causative form of root men- 'to think' (Harper n.d.). This etymological background opens up a new and different way of thinking about the meanings of mentor and mentoring. The person who is acting as a mentor is one who is thinking and reflecting, and this forms the basis of his/her advice. The etymology of the word mentor still possesses the element of authority or superiority in the sense of 'one who admonishes'. Admonition is usually given by a person who has some power over another person, for instance, an officer admonishing a citizen, a parent admonishing a child or a teacher admonishing a pupil. Over time, this binary of superior-inferior has significantly influenced the meaning of mentoring, disguising the nature and work of mentoring as thoughtful and reflective actions. 
Traditionally, mentoring is described as a relationship between two persons, a protégé and a mentor. The traditional understanding of mentoring is problematic in the modern world because it connotes a conservative view of learning, linear transmission of knowledge and asymmetrical power relations between participants (Angelique, Kyle, and Taylor 2002; Tynjälä and Heikkinen 2012). For beginning teachers, this conceptualisation suggests a unidirectional socialisation into existing cultures of schooling, primarily focussed on situational adjustment to a new school environment (Richter et al. 2013).

Current socio-constructivist and sociocultural views of learning have emphasised the importance of social interaction, social learning environments and participation in communities of practice (Tynjälä and Gijbels 2012 , 210). From this point of view, mentoring can be conceived of as a more agentic practice, that is, active construction of knowledge in a social environment rather than merely transmitting knowledge from one person to another (Richter et al. 2013). In the sense of knowledge construction or knowledge transformation, mentoring is an asymmetrical but collaborative relationship, which facilitates exchange and the generation of ideas and may lead to change and innovations in the prevailing situation. The mentor's role is to provide opportunities for growth and development.

Contemporary research suggests new conceptualisations of mentoring that make use of socio-constructivist theories of learning such as co-mentoring, mutual mentoring, collaborative mentoring, peer collaboration, critical constructivist mentoring, dialogical mentoring and reciprocal mentoring (Tynjälä and Heikkinen 2012, 24). These new conceptualisations also suggest new practices centred on group formations such as group mentoring, peer mentoring, mentoring circles and peer-group mentoring (Bozeman and Feeney 2007; Darwin and Palmer 2009; Huizing 2012; Kemmis and Heikkinen 2012; Fyn 2013). These mentoring practices are reported to have the potential to develop and transform the culture of workplaces, while assisting with personal and professional development (Darwin and Palmer 2009, 127).

While having much potential, the concept of mentoring still lacks clear definition or description (Roberts 2000). There are number of other concepts which are closely related to mentoring, such as apprenticeship, coaching and tutoring (Murphy et al. 2005; Topping 2005; Glazer and Hannafin 2006). To add to this conceptual confusion, mentoring is also studied in several academic fields, such as psychology (e.g. American Psychological Association 2014), social psychology (e.g. Hu, Thomas, and Lance 2008), business management (e.g. Higgins and Kram 2001) and human resource development (e.g. D'Abate, Eddy, and Tannenbaum 2003), or from the perspective of social cognitive career theory (e.g. Yang et al. 2013). In these various research traditions, the purpose and aims of mentoring are articulated differently; mentoring is enacted differently and people relate to one 
another differently in various forms of mentoring (Kemmis, Heikkinen, et al. 2014), thus enabling a range of understandings of mentoring and ensuring its nature as a contested concept.

\section{Theory of practice architectures for understanding variety in mentoring}

In this article, we draw on social-constructivist theories of learning to examine mentoring, and so doing emphasises mentoring's inherent sociality as a practice. Further, in order to understand the various ways in which mentoring as a contested but always social practice is taken up and enacted in our Finnish and Australian cases, we employ the lens of practice architectures (Kemmis and Grootenboer 2008). This theoretical lens emphasises the differing arrangements that shape the intersubjective spaces in which participants such as mentors and mentees encounter one another. It thus assists in making sense of how and why particular conceptions of mentoring practices may be taken up in very distinctive ways in differing sites of practice (c.f. Kemmis, Heikkinen, et al. 2014). Participants in the practice encounter one another in social spaces which form the arrangements that prefigure (though not deterministically) the practices within those intersubjective spaces. This emphasis on the prefiguring of mentoring practices - the notion that we are not solely shaped by/shape individuals (such as in a community of practice) but that the practices themselves shape us in the social dimensions in which we encounter one another - marks this lens as distinctive from communities of practice or professional learning communities (Kemmis, Wilkinson, et al. 2014).

The theory of practice architectures draws attention to the three kinds of intersubjective spaces in which participants in mentoring practices encounter one another, i.e. through language, through 'space-time in the material world' and in social relationships (Kemmis, Wilkinson, et al. 2014, 4). Each of these spaces is shaped by particular kinds of arrangements which exist in each of these dimensions and which enable and constrain our thoughts/speech (sayings), our actions (doings) and our relationships with one another and with the material (non-human) world (relatings) (Kemmis and Grootenboer 2008).

In relation to language, participants are enabled and constrained by the cultural-discursive arrangements of specific mentoring practices. For example, the language of a policy discourse about mentoring makes possible particular kinds of sayings and understandings about mentoring, be it as a response to teacher attrition (in the Australian case study), or alternatively, in the Finnish study, workplace well-being and professional development. In relation to space-time in the material world, participants are enabled and constrained by the material-economic arrangements that exist in the material world and which enable and constrain how we do things. For example, does mentoring take place in the formal location of a staffroom or classroom or 
in the more informal space of someone's home or a coffee shop and how do these physical arrangements shape and make possible or preclude particular kinds of conversations and practices?

Finally, in relation to social relationships, participants are enabled and constrained by the social-political arrangements that exist in social space, which enable and constrain how we relate with one another through, for example, the more collaborative social space prefigured by peer-group mentoring or the more traditionally hierarchical relationships connoted by dyadic mentor/mentee arrangements (Wang and Odell 2007; Kemmis, Heikkinen, et al. 2014). Crucially, these three arrangements do not exist in isolation from one another but need to be understood as 'hang[ing] together' (Schatzki 2003) in sites, practices and participants. In sum, how we act and participate in the social world is shaped by these arrangements. The critical point, however, is that in order to realise and bring about transformations to mentoring practice, changes to the three (cultural-discursive, materialeconomic and social-political) arrangements, which shape mentoring practices, need to occur.

Keeping this theoretical outline and literature review in mind, in the remainder of this article, we aim to answer the following research questions:

(1) What are the perceptions and understandings of 'good' mentoring in the Finnish and Australian sites under examination?

(2) What are the practice architectures (i.e., the cultural-discursive, material-economic and social-political arrangements) that enable and constrain different kinds of mentoring practices in these differing sites?

\section{Research settings, material and methodology}

In this section, we outline the nature and sites of mentoring practices in Finland and NSW, Australia and highlight the parameters of the study. We have selected to devote time to an articulation of our analytical processes, given that there is a tendency in qualitative research for trustworthy analytical actions to be underwritten in favour of an explication of the findings. For this explicit process, it is necessary to describe the sites of mentoring practices.

\section{The sites of mentoring practices in Finland and NSW}

Recently, in Finland, mentoring-support practices have been widely developed according to the Finnish model of PGM. This model is funded by the Ministry of Education and Culture and is currently working in over 120 municipalities. PGM is coordinated by the Finnish Network of Teacher 
Induction 'Osaava Verme', which consists of all the teacher education institutions in Finland; that is to say, eight teacher education departments in the universities and five teacher education units in the universities of applied sciences. The development of mentoring in Finland started as a one-on-one pilot in the city of Kokkola. As the pilot progressed to encompass a greater number of municipalities, the model moved towards PGM. The PGM model is based on the ideas of socio-constructivism, dialogue and knowledge sharing (Heikkinen, Jokinen, and Tynjälä 2012). Discussions in PGM occur in groups that consist of both new teachers and their more experienced counterparts. Teachers participate in the groups on a voluntary basis and the mentor of the group is paid for their work. The ideal size of the group varies between four and eight members. The group meets on a regular basis, usually once a month in the afternoon, and preferably in a location away from the teachers' own schools. The group is responsible for planning, organising and implementing its own programme for professional development throughout an academic year (Heikkinen, Jokinen, and Tynjälä 2012).

In contrast to the practices of collegiality, dialogue and 'bottom-up' professional learning underpin the Finnish PGM model; the NSW public education system in Australia has adopted a more traditional, transmissive model of one-to-one mentoring between an experienced teacher and a beginner. Formal mentoring in the NSW public education system has largely arisen in response to national and statewide educational initiatives to improve teacher accountability through the establishment of standards for teachers and leaders (Kemmis, Heikkinen, et al. 2014). New scheme teachers (NST) ${ }^{1}$ are provisionally or conditionally accredited in their initial employment with NSW. However, in order to gain ongoing employment, they must satisfy the standards at the level of Proficient Teacher. Hence, mentoring may be put in place to support novice teachers, particularly those who may be struggling to reach the Proficient Teacher level (New South Wales Government 2013).

In Finland, the motivation for mentoring new teachers is derived from enhancing teacher professional development and professional competence. For the remainder of Europe however, there is a prevalent issue with the retention of early career teachers and this has been addressed widely in research so far (OECD 2000, 2005; European Commission 2007, 2010; Picard and Ria 2011; Eurydice 2013). As such, the EU policy forms one of the (cultural-discursive) practice arrangements shaping Finnish mentoring practices. In contrast to Finland, teacher attrition is a major issue in all states in Australia. Ewing and Manuel (2005) estimated that about $40 \%$ of Australian teachers will leave the profession within 10 years from the beginning of their teaching career for various reasons. A number of explanations were given and researchers identified some of these reasons, such as lack of support and workplace condition and also career planning. Contemporarily, teaching might be a short-term career option for some young teachers who will seek to change careers after 10 years (Ewing and Manuel 2005). From 
this perspective, it is understandable that in Australia, there are serious concerns about accountability and investment of public funds for teacher education (c.f. Long 2009).

\section{The data}

The data have been selected from two larger case studies in Finland and Australia. In the case of Finland, the project generated two different sets of data. In the first instance, the data drew on five semi-structured focus group interviews with mentors and their mentees (total of 16 participants). The issues explored in the focus groups included group composition, motives for participation, how the group was organised and work methods. In the second instance, 14 mentors were asked to write two fictional stories (Mottart et al. 2009; Sikes and Piper 2011), which included elements of their 'real-life-experiences' in a PGM meeting. They were instructed to write one story of a PGM meeting, which they considered to be a total failure, and reflect on what went wrong and for what reasons. The other story was to be written about a successful PGM meeting, and address why it was a success. Thus, the instructions guided the mentors to write not only about the actual experience of mentoring, but also about the practice beyond the experience, the preconditions and arrangements which enabled or constrained that practice.

In the case of Australia, the mentoring data formed a part of a larger action research case study on practices of school transformation, leadership and capacity building in a rural secondary school (Bristol \& Wilkinson, 2014). Two researchers spent one year interviewing staff members as individuals $(N=10)$ and in focus groups $(N=8)$, as well as observing staff meetings $(N=1)$ and staff development days $(N=2)$. School visits were mostly made on Fridays, as this was the day of shared morning teas for the staff and provided us with a way of building a relationship of trust over time with the participants.

Practices of mentoring were evident across three sites of practice within the school: in cross-disciplinary faculty groups, among the staff who participated in a special educational programme for 15-16-year-old students at risk in Years Nine and Ten and in a school-based mentoring programme for NST which was supported by National Partnerships funding. ${ }^{2}$ In conversations with the participants, they were asked to reflect upon experiences of mentoring (being mentored and being a mentor), as well as the ways in which specific incidents of mentoring practices enabled or constrained school transformation, leadership and capacity building. The data that we drew upon for this paper came from the interviews and focus group discussions with the four teachers and one NST involved in this school-based practice $(N=6$ transcripts in total). We selected to do so, given its close comparison with the practices of mentoring designed for new teachers in the Finnish context. 
Interviews and focus groups were audio recorded, while observations were documented using an audio recorder and field journals. All audio recorded material was transcribed. The data that we focus on for analysis draw on interviews with mentors and mentees (the latter were teachers in the first five years of their teaching career).

\section{Analysis}

The analytical process used to mine, make sense of and reinterpret the data was done across two stages. We will describe these stages as first-order analysis and second-order analysis as they illustrate the ways in which we collaboratively scaffolded the analytical development and positioned interpretation as a social process (Barrett 2007).

In the first-order analysis phase, the data for Finland and NSW were analysed separately by the researchers who collected the data in these contexts. As individuals, the researchers subjected the data to content analysis, and then categorised the content into themes. The researchers then met in pairs and collated the emerging themes as particular to Finland or NSW. In the second order of analysis, the thematic data from the two contexts were brought to three meetings between the four researchers and again categorised according to the research questions guiding the study. In these reflective research meetings, the researchers paid attention to what was present or absent in the data across the contexts. At this point, the data were examined for theoretical alignment with the theory of practice architectures.

This phase of the second order of analysis was significant, given our practice of collaborative interpretation and analysis of the data in a concentrated block of three weeks in Australia where the four researchers came together to conduct analysis. During this period, we were able to make explicit our 'thoughts behind the research process' (Sommer 2009, 12), deliberately accepting responsibility for our practices of interpretation. We shared the stories of our research encounters in an attempt to make sense of the nature of the research context and the practices under examination and justify how we were coming to the conclusions that were being drawn. Our collaborative practice acknowledged researchers as 'essentially the instruments of interpretation' (Platt 2002; in Sommer 2009, 14). This collaborative practice also established a measure of trustworthiness and triangulation through our coding practices. In the later phase, our analytical process moved beyond explicit understandings of the practice of mentoring towards more implicit understandings of the practice embedded within the practice architectures which surrounded mentoring (cultural-discursive (sayings), material-economic (doings) and social-political (relatings) arrangements. At this point, through our discussion, we were able to: first, recognise 'potentially ... new forms of practice and new kinds of subjectivities' (Martin and Kamberelis 2013, 677) and second, cultivate 'the possibilities 
inherent in the participant's own understanding' (Watts 2014, 8) as shared in interviews.

We found resemblances to other methodologies for research on practices such as 'zooming in' and 'zooming out' (Nicolini 2012), for at times, we had to pay attention to details ('zoom in') and sometimes, in turn, to the big picture ('zoom out'). Another way to describe our analysis is to use the metaphor of 'bricolage' (Lévi-Strauss 1966; Denzin and Lincoln 2005), referring to a meaning-making process, which is more flexible, fluid, divergent and open-ended compared to traditional scientific knowledge-production activities. Meaning-making bricoleurs combine their imagination with empirical knowledge to meet the diversities and complexities of social practices (Rogers 2012, 2-3). In this study, our meaning-making bricolage included inductive reasoning, which was especially important in the first-order analysis. It also included deductive reasoning as we applied the theory of practice architectures. Moreover, it also included abductive (or retroductive) elements while we asked what still was missing after concluding the first-order analysis.

We have illustrated an analytical process that moved through two phases of data interrogation (Figure 1). This process revealed that the (culturaldiscursive, material-economic and social-political) arrangements emerged differently in the first- and second-order analyses. For instance, many of the material-economic arrangements were explicit after the first-order analysis, but the second-order analysis revealed the more implicit, taken-for-granted, understated cultural-discursive and social-political arrangements, which held the practice of mentoring together across the two contexts. In the secondorder analysis, we asked what was in common or what was different in the

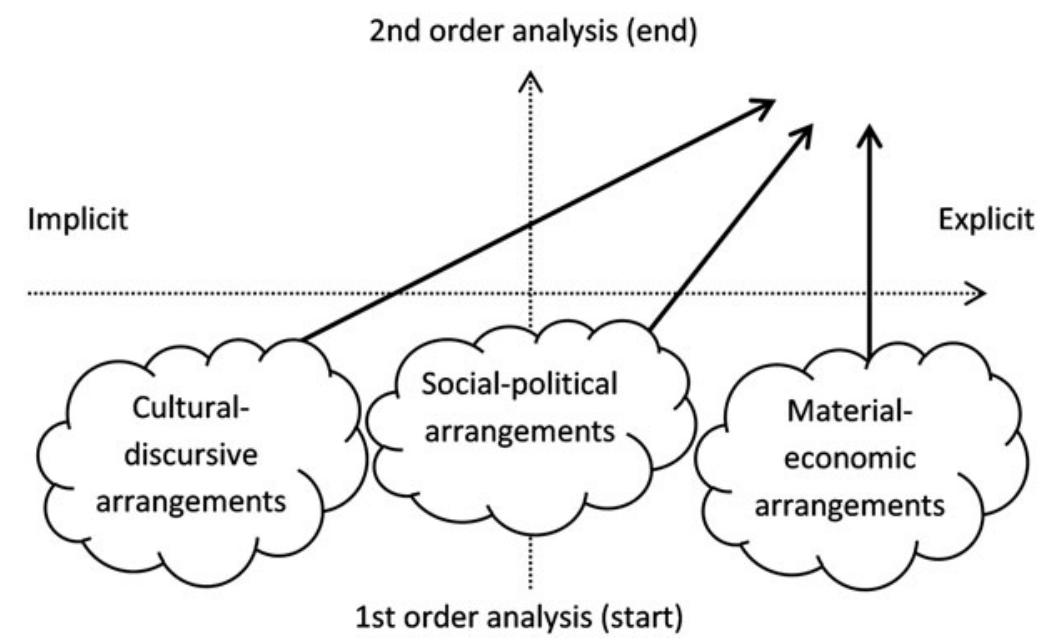

Figure 1. Ontology of data analysis. 
two sets of categories, and asked why something was present and why something was missing. This was how we could bring forward something, which was tacit or implicit beyond the practices.

This process demonstrates the analytical promise of the theory of practice architectures. One of the main aims of that framework is to make the preconditions of practices more explicit. What is least explicit may sometimes be most influential. In this case, some of the more important culturaldiscursive and social-political arrangements were more significant only after the second-order analysis: the elements of power and solidarity, as well as some of the linguistic, cultural and semantic elements that prefigured the practices of mentoring. From this perspective, our findings (see the following section) are in line with some other studies, which have been conducted through the theoretical lens of practice architectures (c.f. Kemmis and Heikkinen 2012; Bristol, Brown, and Esnard 2014; Kemmis, Heikkinen, et al. 2014; Bristol, 2014; Wilkinson and Kemmis 2015).

\section{Results $^{3}$}

The results will be presented in three sections. First, there is a description of the findings from the first-order analysis; the results from each case are introduced as single sections. Second, there is an interrogation of the findings from the second-order analysis. These have been influenced by the researchers' reflective discussion of the themes arising from the first-order analysis.

\section{First-order analysis, Finnish data}

Perceptions and understandings of good mentoring in Finland

In the Finnish data, seven categories emerged from the analysis, time, physical settings, social atmosphere, interaction, unwinding, common agreements and composition of the peer group (Table 1), which were connected to the question of 'what constitutes good mentoring?' These categories were expressed in both negative and positive utterances, which were more or less the opposite expressions of each other (e.g. cosy couch vs. uncomfortable chair).

Time had two dimensions in the data: time for the meetings and time in the meeting. When people were working in a group, it was important that there was sufficient time for the meeting, the date was suitable for everyone and the meetings had some kind of continuity and stability (e.g. a certain day in a month). Also, the time for planning and the use of time within the meeting emerged as a critical issue. For instance, time to talk had to be equally divided between the participants, participants appreciated that the reserved time was planned well and used in a beneficial way, and that participants followed the time plan that was agreed in the group. These 


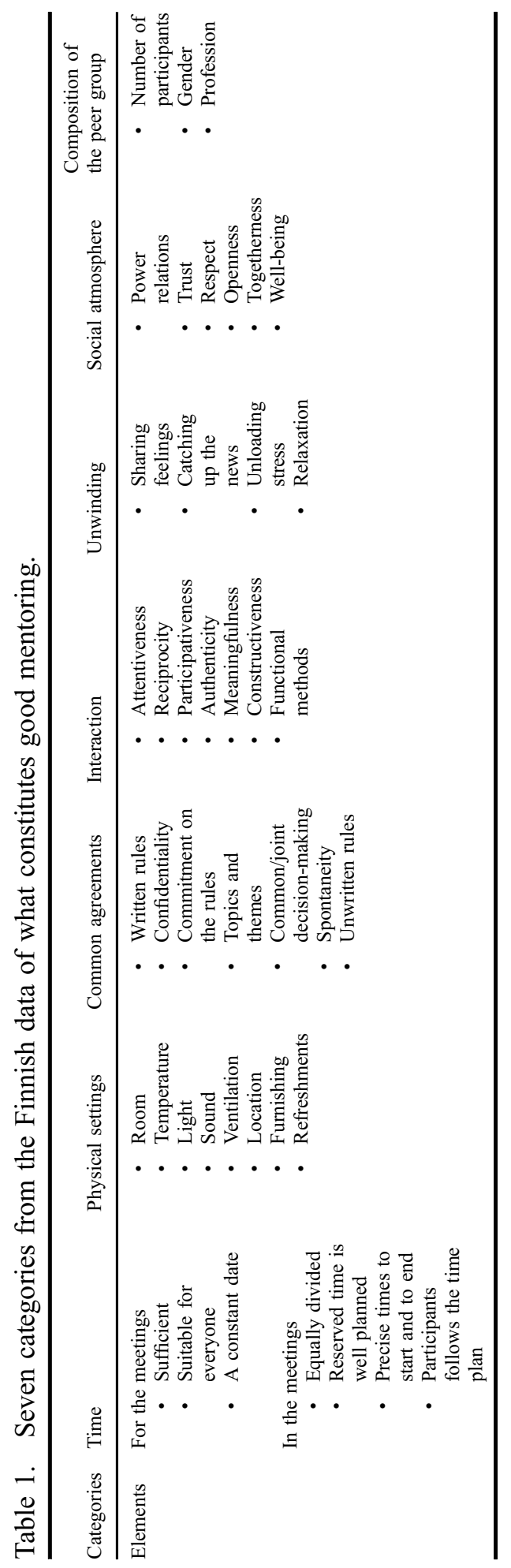


practices demonstrated that teachers valued time as a critical resource and were not willing to waste it.

Another category was physical settings. For the participants, the actual site involved many meaningful elements, which affected the outcome of the meeting. Adjectives were used to describe the physical settings including: uncomfortable chair, draughty windows, noisy music, beautiful and cosy place, warm room and tasty biscuits. In most situations, the described place for the mentoring meeting was something other than the teachers' own classroom. As one participant reflected, the 'best place to air your thoughts is far away from your own class'.

Time and physical settings were one part of the common agreements that the participants planned and agreed to in the group. These agreements were important to ensure that the group worked and functioned effectively, and that decision-making was democratic and involved every member of the group. First, the group decided together where they would meet, the dates and times for the meetings and the topics and themes they wanted to address. Secondly, to ensure commitment and confidentiality, the group created rules, which influenced how the participants would work. This also involved agreements on how to talk about issues and about the group itself to persons who were not members of the group. Although the group formed these rules, it did not prevent spontaneity during the meetings and plans were modified during meetings if there seemed to be urgent, relevant issues to talk about. Some statements also referred to other 'unwritten rules', such as implicit social norms and the ways participants were expected to behave in the group.

The expressions for the category of interaction mirrored a reciprocal and constructive action in a participative group. Participants could be themselves and the group took care to ensure that all individuals had the opportunity to contribute to the discussion. Participants indicated that they preferred a discussion, which was constructive, and eventually led to problem-solving or a solution, so that participation was meaningful for the group members. The requirement of 'attending' or 'being present' for the participants was expressed in the data and this was connected to the need for different types of stimulation besides the discussion. For instance, picture cards were used to help to express emotion or a form of drama was employed for those who preferred to express feelings kinesthetically. These were named as functional methods in the categorising.

The category of unwinding is related to interaction, but was regarded as a separate category because of the specific role that it played in the interaction. It created opportunities for 'catching up while having coffee and at the same time we talked about the day's events so far and unloaded our feelings'. Unwinding was something that the participants did when they arrived. Teachers started to catch up on news and depending on the previous events of the day, they unloaded emotional stress, shared good feelings or just had 
coffee or tea and relaxed. For the participants, this seemed to be important because they had the opportunity to share the things that were puzzling them and/or orientate themselves to upcoming discussion. This was also one of the situations when teachers said that they received emotional support.

The category of social atmosphere combined the expressions that described the participants' experiences of social relatings and social interaction in the group. The mentoring practice is specifically named as peergroup mentoring and this element of peerness or equity was related to expressions that reflected more collegial power relations. The individuals of the group were viewed as important by other members of the group, with clear protocols that no one person should dominate or be dismissive of other's points of view. To support equity in the group, the individuals needed to experience trust, respect and openness. Togetherness or the cohesion of the group was mentioned as it was one of the aims or objectives for the group. Well-being was expressed as a benefit or outcome in the utterances: teachers felt satisfied or relieved after the meeting.

The final category was the composition of the group and usually the expressions indicated how many persons were involved in the group and their gender. The ideal size of the group was noted as ranging from five to eight persons and because of the general division of female and male teacher in Finland, participants observed they would have liked to have more male teachers in the groups. Groups were formed in different ways, for instance, participants having similar roles such as subject teachers. Alternatively, they may have been teachers from different grade levels, as long as they were interested in some of the same themes.

\section{First-order analysis, NSW (Australia)}

Perceptions and understandings of good mentoring in NSW, Australia

In the context of NSW, mentoring often occurs in one-to-one, hierarchical arrangements between a senior teacher and a NST. This positional set-up facilitates an understanding of mentoring that may be more in line with a transmissive model. The NSW data illustrate some of the prefiguring features (Table 2) associated with a transmissive model of mentoring through directed activities intended to ensure accreditation and facilitate teacher quality and competency. These undertakings were shaped by a tacit understanding expressed by one mentor in relation to NST as 'enthusiastic but with still a lot to learn'.

At Hilltop High School - a small rural secondary school serving a low socio-economic student population - formulating a shared purpose for mentoring included initial conversations between mentors and mentees. These conversations established a set of personal performance indicators that the mentee would 'want to work on'. In this conversation, the mentee, with the 


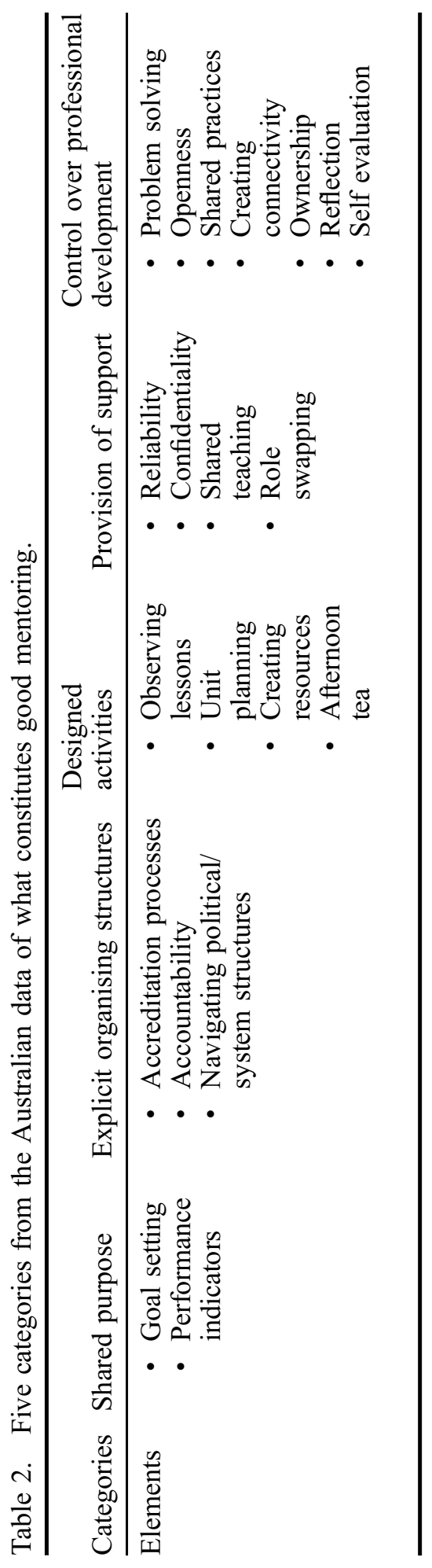


help of the mentor, sets goals that were met during the period of time allocated for the mentoring relationship. These goals and indicators were significant as they framed a conversation in relation to expectations of and for mentoring and being mentored.

Mentors were expected to design and articulate the range of explicit organising structures, which govern teaching and more particularly the accreditation process for NST. Mentoring, in this case, served to help NST navigate the technologies associated with being a teacher in NSW. Parallel to the existing standards for teacher quality were implicit expressions of mistrust over the quality of university graduates entering into teaching. As one mentor, 'Celeste', suggested in regard to teacher training, 'the Dip.Ed. Course needs to change', for Head Teachers at the school identified newly graduated NSTs needing 'extra assistance in a lot of areas'. Mentoring, teachers contended, was to ensure that the 'quality of the teaching continues or is upheld' (Celeste) and that accreditation was possible and successful.

In these circumstances, the mentor's role was conceived in highly gendered terms as being like a 'mother hen', admonishing and advising the mentee about the prerequisites for teaching and staffing responsibilities. Celeste, in constructing a fellow mentor, Sally, as a 'mother hen', outlined this understanding of the mentor:

Being the more senior, she was very much about reinforcing school policies, codes of conduct, I like to say the political side... making sure that..., their content of the lessons was substantial enough to go through from pre-requisite to $\mathrm{HSC}^{4} \ldots$ we call her the mother hen ... she looked at the psychological well-being (Celeste).

In response, Sally accepted this mother-hen construction of her mentoring work, given that she characterised the mentees as 'the little chickens under our wing' who needed to be looked after.

The organising structures for good mentoring in this more transmissive model were also supported by designed activities, which served to reinforce and build upon the pedagogical elements of teaching learnt while in preservice teacher training. Mentoring relationships were navigated through activities such as lesson observations, unit planning, creating resources for lessons and sharing afternoon tea as a way of monitoring development in a less formal manner. Through these activities, Celeste constructed the mentor's role as akin to a swim coach and lifeguard, protecting against the eventuality that a new teacher be thrown 'in the deep end of the pool and them not be ... able to swim'. This protective notion (psychological care) needs to be understood against a background of national concerns for high teacher attrition rates. It was summed up in Celeste's argument that 'our NST who are young need lots of recognition' and support to 'keep them in teaching', as they learn to play the game of teaching. As such, good 
mentoring as a notion of excellence in professional performances was closely linked, in this instance, to a form of clinical professional development for the mentee.

Significantly, 'psychological care' can also be understood as the provision of support. This sense of good mentoring is more in line with collaborative and community models of mentoring (Tynjälä and Gijbels 2012). That is, it can be understood as a negotiated and reciprocal practice between mentor and mentee, in which the pair navigates system demands for quality indicators and accreditation. At Hilltop High School, this involved mentors and mentees swapping roles and providing critical and evaluative feedback on each other's observation lessons. Both mentors and mentees learned by 'watching someone else teach'. This was where mentors such as Celeste in a more dialogical relationship with the mentee - were able to reflect on her weaknesses. Unsurprisingly, however, collaborative models of mentoring appeared to be more evident where there were more symmetrical power relations, i.e. between the NST mentors, Celeste, Freida and Sally, rather than mentors and mentees. In reflecting on their team relationship, Freida, Celeste and Sally recognised that they 'needed to be very supportive of one another ... right from the outset ... to be a strong team together' (Freida); 'celebrating little victories' (Sally), in their work as mentors and in their relationships with each other and the mentees.

These forms of support ensured a measure of control over professional development for the mentee and the mentor. Reflection and self-evaluation fed autonomous and professional action, facilitated problem-solving, encouraged openness and the ability to share practices with others and created connectivity between peers, internal and external to the school and between mentees and mentors. The latter was critical for the NST as it built a sense of belonging to a professional community, and thus relieved one of the challenges of being a beginning teacher in a challenging, high poverty, rural educational setting. ${ }^{5}$

\section{Second-order analysis: 'What is good mentoring?'}

After having inductively categorised the elements of 'good mentoring' in the Finnish and in the NSW data, the second phase of analysis involved a collaborative comparison of the first-order analysis of both studies. In this analysis phase, we compared the first-order analysis through the lens of our second research question, namely, what are the practice architectures that enable and constrain different kinds of mentoring practices in the two different sites of Finland and NSW, Australia? What became clear in this process is that very different kinds of mentoring practices had developed in both sites due to the differing kinds of projects or underlying purposes which held these practices in place. A project is the end result or purpose of a practice and provides an answer to the question, what is the purpose of this 
practice? (Kemmis et al. 2009). The key differences of these two sites have been summarised in the Table 3.

The project of a practice creates the enabling and constraining preconditions (cultural-discursive, material-economic and social-political arrangements) that make particular kinds of practices of mentoring (and not others) possible. For instance, in NSW, new teachers must achieve accreditation at the end of the first three years of their teaching career. Failure to do so will lead to exiting from the teaching profession - a low-trust environment. In Finland, there is no accreditation process as new teachers are assumed to already have the necessary professional skills and competencies after graduation required for successful teaching practice - a high-trust environment. It is these contrasting sets of practice architectures which form the enabling and constraining preconditions holding together the differing practices of mentoring in both national contexts. Specifically, in terms of the culturaldiscursive arrangements of mentoring in the Finnish case, the purpose of the national project of peer-group mentoring has been to create well-being at work for new teachers through the professional development afforded by peer-group mentoring. A secondary purpose is to provide commencing teachers with emotional support in their first years of teaching. Hence, the language of mentoring in the Finnish case draws from national policy which emphasises workplace well-being and emotional support. From this project flows a different set of mentoring arrangements and subsequent practices, captured in the category of 'unwinding' in the first-order categorisation of the Finnish data. Participants' differing sayings ('coffee' and 'cosy atmosphere'), doings (an emphasis on providing good coffee and delicious food) and more collegial relatings ("catching up ... unloaded our feelings') capture these dominant policy discourses.

In terms of the cultural-discursive arrangements of mentoring in the Australian case, the purpose of the NSW project has resulted from a

Table 3. Key differences between Finland and NSW from second-order analysis.

\begin{tabular}{|c|c|c|}
\hline \multirow[b]{2}{*}{ Difference } & \multicolumn{2}{|c|}{ Sites of the mentoring practice } \\
\hline & Finland & NSW, Australia \\
\hline $\begin{array}{l}\text { Requirements for } \\
\text { full teacher } \\
\text { qualification }\end{array}$ & $\begin{array}{l}\text { Five years pre-service } \\
\text { teacher education }\end{array}$ & $\begin{array}{l}\text { Four years pre-service teacher } \\
\text { education }+1-3 \text { years of } \\
\text { accreditation process }\end{array}$ \\
\hline $\begin{array}{l}\text { Mentoring } \\
\text { practice }\end{array}$ & Peer-group mentoring & One-to-one mentoring \\
\hline Primary project & $\begin{array}{l}\text { Support teachers' } \\
\text { professional development } \\
\text { and work well-being }\end{array}$ & $\begin{array}{l}\text { Solve the problem of teacher } \\
\text { attrition }\end{array}$ \\
\hline Secondary project & Emotional support & $\begin{array}{l}\text { Teacher quality, accountability } \\
\text { and efficiency }\end{array}$ \\
\hline
\end{tabular}


system-identified need to stem the high numbers of new teachers leaving the profession in the early career. A secondary project is a long-term neoliberal education agenda which emphasises teacher quality, accountability and efficiency. Hence, the predominant sayings of the NSW teacher mentors in our first-order analysis reflected these dual projects, with their discussion of one of the purposes of mentoring as being about 'reinforcing school policies, codes of conduct ... the political side' (our italics). The various projects of mentoring in the NSW case also reflected a different aspect of mentoring's etymological origins, that is, 'one who admonishes'. It was the more instrumentalist project underlying mentoring policies in NSW, linked to an explicit 'admonitory' set of relatings, emphasising power over the mentee, ('codes of conduct'), that fostered a more technicist and rationalist approach to mentoring practices. In contrast to the Finnish case, sayings which emphasised more humanistic or collegial sets of relatings were marginalised. However, they were not utterly unsayable. At one point, Sally noted that in order to foster a greater sense of trust between the NST and mentors, the mentors had instigated a more informal afternoon tea, where new teachers could talk about how things were going in a more relaxed atmosphere.

In terms of the material-economic arrangements that 'exist in the dimension of physical space-time' (Kemmis, Wilkinson et al. 2014, 4), in the Finnish case, time was a constant theme in participants' sayings about mentoring. It enabled and constrained mentoring practices in relation to two factors - the lack of time for teachers to do their work and the constant juggle to negotiate the professional demands associated with peer-group mentoring, alongside one's personal demands (e.g. finding time to meet outside school hours). In the NSW case, time did not emerge as a crucial element in participants' sayings. One of the reasons may be the different kinds of funding that support mentoring in the two case studies. In Finland, funding was provided for teachers to train as mentors. However, it was not provided for teacher release in order for teachers to take part in peer-group meetings in school time. Hence, a different set of doings flowed from these arrangements in terms of meetings taking place outside school hours. Attendance was voluntary and the group structure of the mentoring necessitated more negotiations to accommodate professional and personal demands.

In contrast, Hilltop High School had gained National Partnerships funding and the principal had elected to use some of these funds to support the release of both new and more experienced teachers (mentees and mentors) in school time. The emphasis was upon the development of mentee practice, with an implicit assumption that mentors did not need or require training (this assumption was challenged by mentors in their interviews). Clearly related to the accreditation and accountability project of this mentoring practice, this material-economic arrangement facilitated mentors' doings. Examples of these doings included observations of mentees' classes; 
demonstrations of 'good' pedagogical practice through mentees' observing mentors' (and other experienced teachers') classes; mentors working with mentees to develop their teaching programmes; and mentors providing a range of supports towards building mentees' accreditation portfolio. These doings of mentorship practice bundled together with specific sayings of mentorship. For instance, mentors in the NSW case study identified that using explicit language in order to translate the language of accreditation into understandable chunks was part of the 'good' mentoring practice. These sayings and doings of mentoring practice were bundled together with specific kinds of relatings. For example, mentoring practices such as observations of mentees' teaching and facilitation of accreditation reflected a more 'top-down' approach to mentoring.

Another aspect of the material-economic arrangements was the physical setting in which mentoring took place. This was a focus of many sayings in the Finnish case study. Given the emphasis of peer-group mentoring was on supporting new teachers' workplace well-being, it was critical that a space be found for groups that was not in the workplace, had pleasant and congenial surroundings to induce a spirit of relaxation and was quiet and private enough to allow for the exchange of confidential aspects of work. The physical setting arose as a predominant understanding of what participants understood constituted 'good' mentoring practice. In contrast, physical setting, for the reasons outlined above, did not emerge as a critical issue in the NSW case. Mentoring took place in the workplace and was regularly scheduled in the school's meeting rooms where the formality of the practice and its association with improvement of workplace performance was clearly connoted to mentor and mentees alike - a constant reminder of the accountability agenda that underpinned this mentoring project.

Both the composition of the Finnish peer groups such as their size (between five and eight was considered an ideal number) - and the fact that mentoring took place in a group setting - were critical aspects of the material-economic arrangements of mentoring practice that shaped the relatings of mentorship practice. For instance, the intersubjective space constructed within these groups was underpinned by Finnish values of social democracy, connoted in the appellation, peer-group mentoring (our italics). Noteworthy was the fact that although the groups were 'led' by a mentor, the groups combined a clear mix of experienced and less experienced teachers who were seeking on a voluntary basis greater enhancement of their workplace well-being and professional development. Hence, in relation to the social-political arrangements or preconditions which fostered particular kinds of relatings between mentors and mentees, the notion of equity amongst peers, including that between mentors and mentees, shaped the intersubjective space in which participants encountered one another within peer groups. This is not to idealise or gloss over asymmetrical power relations between participants in the groups, but to foreshadow the types of 
social-political arrangements, which enabled the fostering of more equitable practices of mentoring. Hence, in the groups, good mentoring practice was characterised as forming collaborative relationships. Mentors played a less obtrusive role in the Finnish context, with an emphasis upon new teachers and mentors as co-constructors of knowledge. Hence, the formalised role of the mentor switched in the group between advising, giving constructive feedback, being silent and learning. Good mentoring practice was constructed as a reciprocal set of relatings focused on shared meaning-making, characterised through a range of sayings that emphasised attentiveness, reciprocity, participatory, authenticity and meaningfulness. In this set of arrangements, there was a presumption of agency, ownership and power to build professional identity and a pedagogical disposition. Mentees' subject location was signified as one of trust, respect and autonomy - a valued teaching professional who brought knowledge and competence to the group.

At Hilltop High School, a more transmission-based set of mentoring practices for NST was enabled through the arrangements of mentoring pairs - a traditional, dyadic, unidirectional set of relatings, which shaped mentoring as an intersubjective space. There were clear tensions between the accountability and standards approach to mentoring which emanated from government policy and funding models and the more invisible, but equally important, emotional labour of supporting NST. This labour was captured in highly gendered terms when one mentor was described as the 'mother hen' and she, in turn, described NST as her 'little chicks'. They connoted a very different set of subject locations for mentors and mentees from the relatings captured in the Finnish sayings of 'peers' and 'peer group'.

\section{Discussion and conclusion}

As stated in the introduction, our study had two aims. In the first instance, we conceptualised mentoring ontologically as a social practice. This offered a new perspective to the research literature on mentoring and the manifestations of what ontologically can be thought to be good mentoring. Comparative research setting offered a tool to reveal the differences and similarities of the two practices, but not to decide whether one practice was better than the other one. Such a decision is irrelevant because it is evident that these two practices are solving different kind of problems, in other words, they have different kind of projects. In the discussion that follows, we will highlight the implications of employing a practice ontological perspective to understand and to inquire into what is good mentoring in terms of teacher induction, as well as make recommendations for policies and practices at the system level.

We have focused on understanding the underlying practice conditions, which prefigure different mentoring practices in different social sites. The theory of practice architectures provided an appropriate lens through which 
mentoring arrangements were identified: the practice architectures of mentoring. Comparisons between the two sites were illuminating as they helped to explicate how these practice architectures constructed different kinds of understandings or 'sayings', activities or 'doings' and 'relationships' or 'relatings' (Kemmis and Grootenboer 2008) of mentoring enabled and/or constrained by the cultural-discursive, material-economic and social-political arrangements in the two different sites. The different practice traditions, and their associated arrangements, influenced what came to be the ontological givens or manifestations of mentoring in Finland and in NSW, Australia. The findings in this paper, then, have implications for the ontological specificity of mentoring as an imagined practice (mentoring as a concept) and as a lived practice (enacted in social arenas in temporal spaces). More so, our findings point to the problematic nature of adopting international positions on mentoring, as a homogenising practice understood, lived and engaged equally across a range of dissimilar sites locally, regionally and internationally.

At a more universal scale, we must be aware of power and language beyond the actual actions, which are interconnected or 'bundled together' in many ways with the actual activities and actions of mentoring in the material-economic world (Schatzki, 2002). For example, concepts such as 'novice' or 'novice teacher', which are often used in the context of mentoring, connote historical practices, such as preparing members of religious orders in the Catholic Church and apprenticeship practices in the guilds of the Middle Ages, where less experienced young people were guided by more experienced and older role models (Kemmis and Heikkinen 2012). If we use these kinds of expressions, the social relations between the persons involved in the mentoring process are prefigured accordingly.

Of significance as well are (1) the interrelationship between emerging or pre-existing practice arrangements and the particular practice traditions (the historical traces which inform particular site's practices) of the site and (2) the impact of this relationship on a mentoring practice. This is evident in the ways in which local circumstances and national politics affect the practices of mentoring. The significant differences in traditions configure mentoring in very distinctive ways, which also facilitate the contested nature of mentoring (Kemmis, Heikkinen, et al. 2014). In NSW, Australia, a highly centralised and hierarchical public education system prefigured the emergence of more transmissive models of NST mentoring, whereas in Finland, a political tradition of social democracy underpinned more collegial mentoring practices focused on promoting professional development and well-being. This correlates with the finding that mentoring practice, which follows the constructivist principles of learning, fosters professional development and well-being more appropriately (Richter et al. 2013). However, dyadic mentoring models do not exclude principles of constructivism automatically. There are dyadic applications which follow these principles, 
such as co-mentoring, mutual mentoring, collaborative mentoring, peer collaboration, critical constructivist mentoring, dialogical mentoring and reciprocal mentoring (Tynjälä and Heikkinen 2012, 24).

An ontological designation of good mentoring also has implications for the ontological nature of the inquiry that goes into an investigation intended to apprehend or stabilise a definition of good mentoring. This requires a research practice of a different social form amongst researchers, i.e. one which is enabled and sustained through orders and arrangements that promote and prefigure shared interrogations of: (1) researcher conceptual and language understandings, (2) research sites, (3) research practices, (4) interpretations of data and (5) emerging understandings of the complexity of practices across sites. Thus, a site ontological perspective of good mentoring can be best accessed through an inquiry that is both philosophically and socially located in the practice traditions of the practice being problematised.

Additionally, there are system implications for the practice and consideration of good mentoring as ontologically located. In the light of the global education reform movement (GERM; Sahlberg 2011), the notion of mentoring as an ontological practice has implications for policy-makers and the ways in which policies are evaluated and implemented. Given the social and ontological nature of mentoring as a practice, mentoring must be recognised as a localised response to teacher professional development, rather than - as in European Union - a unified model to be homogenously applied. What this suggests is that systems of mentoring and its associated practices cannot be imported or exported and transplanted in new sites without a concurrent impact upon the authenticity and cohesion of the practice (as in the NSW case, where mentoring is functioning as a practice in transition, i.e. between transmissive and more collaborative practices).

For practitioners and schools, these findings have implications for the ways in which they understand the unfolding of a social practice in educational projects such as those geared towards teacher development. There needs to be an awareness of the ways in which particular sayings, doings and relatings and their attending arrangements can be employed to transform and substantiate good mentoring as a practice, one that is relevant to the needs and learning of mentee, the mentor and the wider professional community.

\section{Notes}

1. New Scheme Teacher refers to a category of teachers in NSW who were employed after October 2004 or returned to duty after a long absence (five years or more) after this date. These teachers, under the guidelines of the Teacher Accreditation Act of 2004 and the Board of Studies, Teaching and Educational Standards Act, were expected to complete an accreditation process in the first five years after their appointment or return to duty. This is part of the NSW Department of Education and Communities requirements for 
employment and approval to teach in NSW (https://www.det.nsw.edu.au/poli cies/employment/recruit/tchr_acred/PD20050165.shtml).

2. The Smarter Schools National Partnerships Programme funding was provided to schools by the Australian Government via state and territory governments. The funding was to be used to address disadvantage, support teachers and school leaders and improve literacy and numeracy outcomes (http://smarter schools.gov.au/).

3. There are obvious differences in the ways in which the voice of participants in the Finnish and Australian data were presented. In the Finnish data, no pseudonyms were used because these reflected a composite of participants' ideas captured through the fictional stories created by the participants. In the Australian data, pseudonyms were used as these reflected the participants' individual perspectives.

4. Higher School Certificate (HSC) is a an end of secondary school qualification awarded to students in Years 11 and 12 in NSW.

5. The middle ground positioning (that is, somewhere in the continuum between transmissive and more collaborative models) of 'good mentoring' at Hilltop High reflected a growing orientation in NSW public schools towards more site-based practices for professional development and capacity building. These gestures towards more collaborative mentoring were mirrored in controversial statewide policies such as Local Schools: Local Decisions, where principals recently have been given the authority (and by implication autonomy) and funding to determine the forms of professional learning and support relevant to them and their school context.

\section{ORCID}

Jane Wilkinson (D) http://orcid.org/0000-0002-0727-0025

\section{References}

American Psychological Association. 2014. Introduction to Mentoring: A Guide for Mentors and Mentees. Accessed 11 February 2014. http://www.apa.org/educa tion/grad/mentoring.aspx

Angelique, H., K. Kyle, and E. Taylor. 2002. "Mentors and Muses: New Strategies for Academic Success." Innovative Higher Education 26 (3): 195-209.

Aspfors, J. 2012. "Induction Practices: Experiences of Newly Qualified Teachers." PhD diss., Åbo Akademi University.

Barrett, J. R. 2007. "The Researcher as Instrument: Learning to Conduct Qualitative Research through Analysing and Interpreting a Choral Rehearsal." Music Education Research 9 (3): 417-433.

Bozeman, B., and M. K. Feeney. 2007. "Towards a Useful Theory of Mentoring." Administration \& Society 39 (6): 719-739.

Bristol, L. 2014. "Leading-for-Inclusion: Transforming Action through Talk." International Journal of Inclusive Education 1-19. doi:10.1080/13603116.2014. 971078.

Bristol, L., L. Brown, and T. Esnard. 2014. "Socialising Principals: Early Career Primary School Principals in Trinidad and Tobago." Journal of Educational Administration and History 46 (1): 17-37.

Bristol, L., and J. Wilkinson. 2014. "Quality Education as Worthwhile!? Practices as Interconnected Sites for and of Transformation in a School Setting." In 
Enabling Education. Research in Educational Sciences 66, edited by L. T Heikkinen Hannu, Josephine Moate and Marja-Kristiina. Lerkkanen, 189-206. Jyväskylä: Finnish Educational Research Association.

Colley, H. 2003. "Engagement Mentoring for 'Disaffected' Youth: A New Model of Mentoring for Social Inclusion." British Educational Research Journal 29 (4): 521-542.

D’Abate, C., E. Eddy, and S. Tannenbaum. 2003. "Literature-based Approach to Understanding Mentoring, Coaching, and Other Constructs that Describe Developmental Interactions." Human Resource Development Review 2 (4): 360-384.

Darwin, A., and E. Palmer. 2009. "Mentoring Circles in Higher Education." Higher Education Research \& Development 28 (2): 125-136.

Denzin, N. K., and Y. S. Lincoln, eds. 2005. The SAGE Handbook of Qualitative Research. 4th ed. Thousand Oaks, CA: Sage.

European Commission. 2007. Improving the Quality of Teacher Education. Communication from the Commission to the Council and the European Parliament. Brussels: European Commission. Accessed March 27. http://www.see-edu coop.net/education_in/pdf/com392_en.pdf

European Commission. 2010. Developing Coherent and System-wide Induction Programmes for Beginning Teachers: A Handbook for Policymakers. European Commission Staff Working Document SEC (2010) 538 Final. Brussels: Commission of the European Communities.

Eurydice. 2013. Key Data on Teachers and School Leaders in Europe. Eurydice Report 2013 Edition. Brussels: Education, Audiovisual and Culture Executive Agency Eurydice and Policy Support.

Ewing, R., and J. Manuel. 2005. "Retaining Quality Early Career Teachers in the Profession: New Teacher Narratives." Change: Transformations in Education 8 (1): $1-16$.

Fyn, A. F. 2013. "Peer Group Mentoring Relationships and the Role of Narrative." The Journal of Academic Librarianship 39 (4): 330-334.

Glazer, E. M., and M. J. Hannafin. 2006. "The Collaborative Apprenticeship Model: Situated Professional Development within School Settings." Teaching and Teacher Education 22 (2): 179-193.

Harper, D. n.d. "Online Etymology Dictionary." Accessed 2 February 2014. http:// www.etymonline.com/

Heikkinen, H., H. Jokinen, and P. Tynjälä, eds. 2012. Peer-Group Mentoring for Teacher Development. Milton Park: Routledge.

Higgins, M. C., and K. E. Kram. 2001. "Reconceptualizing Mentoring at Work: A Developmental Network Perspective." Academy of Management Review 26 (2): 264-288.

Hu, C., K. M. Thomas, and C. E. Lance. 2008. "Intentions to Initiate Mentoring Relationships: Understanding the Impact of Race, Proactivity, Feelings of Deprivation, and Relationship Roles." The Journal of Social Psychology 148 (6): 727-744.

Huizing, R. 2012. "Mentoring Together: A Literature Review of Group Mentoring." Mentoring and Tutoring: Partnership in Learning 20 (1): 27-55.

Ingersoll, R. M., and T. M. Smith. 2004. "Do Teacher Induction and Mentoring Matter?" NASSP Bulletin 88: 28-40.

Kane, R. G., and A. Francis. 2013. "Preparing Teachers for Professional Learning: Is there a Future for Teacher Education in New Teacher Induction?" Teacher Development 17 (3): 362-379. 
Kemmis, S., C. Edwards-Groves, J. Wilkinson, and I. Hardy. 2012. "Ecologies of Practices." In Practice, Learning and Change: Practice Theory Perspectives on Professional Learning, vol. 8 of Professional and Practice-based Learning, edited by P. Hager, A. Lee, and A. Reich, 33-49. Dordrecht: Springer.

Kemmis, S., and P. Grootenboer. 2008. "Situating Praxis in Practice: Practice Architectures and the Cultural, Social and Material Conditions for Practice." In Enbabling Praxis: Challenges for Education, edited by S. Kemmis and T. J. Smith, 37-64. Rotterdam: Sense Publisher.

Kemmis, S., and H. Heikkinen. 2012. "Future Perspectives: Peer-group Mentoring and International Practices for Teacher Development." In Peer-group Mentoring for Teacher Development, edited by H. Heikkinen, H. Jokinen, and P. Tynjälä, 144-170. Milton Park: Routledge.

Kemmis, S., H. Heikkinen, J. Aspfors, G. Fransson, and C. Edwards-Groves. 2014. "Mentoring as Contested Practice: Support, Supervision and Collaborative Self-development." Teaching and Teacher Education 43: 154-164.

Kemmis, S., J. Wilkinson, C. Edwards-Groves, I. Hardy, P. Grootenboer, and L. Bristol, eds. 2014. Changing Practices, Changing Education. Singapore: Springer.

Kemmis, S., J. Wilkinson, I. Hardy, and C. Edwards-Groves. 2009. "Leading and Learning: Developing Ecologies of Educational Conference." Paper presented at the Australian Association of Research in Education Conference, Canberra, ACT, November 29-December 3.

Lévi-Strauss, C. 1966. The Savage Mind. Chicago, IL: University of Chicago Press.

Long, J. 2009. "Assisting Beginning Teachers and School Communities to Grow through Extended and Collaborative Mentoring Experiences." Mentoring and Tutoring: Partnership in Learning 17 (4): 317-327.

MacIntyre, A. 2007. After Virtue. A Study of Moral Theory. 3rd ed. Notre Dame: University of Notre Dame Press.

Martin, A. D., and G. Kamberelis. 2013. "Mapping not Tracing: Qualitative Educational Research with Political Teeth." International Journal of Qualitative Studies in Education 26 (6): 668-679.

Mottart, A., S. Vanhooren, K. Rutten, and R. Soetaert. 2009. "Fictional Narratives as Didactical Tools: Using Frank McCourt's Teacher Man in Pre-service Teacher Education." Educational Studies 35 (5): 493-502. doi:10.1080/ 03055690902879143.

Murphy, K. L., S. E. Mahoney, C.-Y. Chen, N. V. Mendoza-Diaz, and X. Yang. 2005. "A Constructivist Model of Mentoring, Coaching and Facilitating Online Discussions." Distance Education 26 (3): 341-366.

New South Wales Government: Department of Education and Communities. 2013. "Accreditation of Teachers in New South Wales Government Schools Policy." Accessed 29 May 2014. https://www.det.nsw.edu.au/policies/employment/re cruit/tchr acred/PD20050165.shtml

Nicolini, D. 2012. Practice Theory, Work and Organization. Oxford: Oxford University Press.

OECD. 2000. From Initial Education to Working Life. Paris: OECD.

OECD. 2005. Teachers Matter: Attracting, Developing and Retaining Effective Teachers. Paris: OECD.

Oxford University Press. n.d. Oxford English Dictionary. Accessed 2 February 2014. http://www.oed.com 
Picard, P., and L. Ria. 2011. Beginning Teachers: A Challenge for Educational Systems - CIDREE Yearbook 2011. Lyon: ENS de Lyon, Institut français de l'Éducation.

Platt, J. 2002. "The History of the Interview." In Handbook of Interview Research: Context and Method, edited by J. Gubrium and J. Holstein, 33-54. Thousand Oaks, CA: Sage.

Richter, D., M. Kunter, O. Lüdtke, U. Klunsmann, Y. Anders, and J. Baumert. 2013. "How Different Mentoring Approaches Affect Beginning Teachers' Development in the First Years of Practice." Teaching and Teacher Education 36: $166-177$.

Roberts, A. 2000. "Mentoring Revisited: A Phenomenological Reading of the Literature." Mentoring \& Tutoring: Partnership in Learning 8 (2): 145-170.

Rogers, M. 2012. "Contextualizing Theories and Practices of Bricolage Research." The Qualitative Report 17 (7): 1-17.

Sahlberg, P. 2011. Finnish Lessons: What Can the World Learn from Educational Change in Finland. New York: Teachers College Press.

Schatzki, T. R. 2002. The Site of the Social: A Philosophical Account of the Sonstitution of Social Life and Change. University Park: Pennsylvania State University Press.

Schatzki, T. 2003. "A New Societist Social Ontology." Philosophy of the Social Sciences 33: 174-202. doi:10.1177/0048393103032002002.

Sikes, P., and H. Piper. 2011. "Researching Allegations of Sexual Misconduct in Schools: The Need for a Narrative Approach." Sexuality Research and Social Policy 8 (4): 294-303.

Sommer, C. A. 2009. "Gathering Wool: Reflections on Conducting Qualitative Research." Journal of Poetry Therapy: The Interdisciplinary Journal of Practice, Theory, Research and Education 22 (1): 11-20.

Topping, K. J. 2005. "Trends in Peer Learning." Educational Psychology 25 (6): 631-645.

Tynjälä, P., and D. Gijbels. 2012. "Changing World: Changing Pedagogy." In Transitions and Transformations in Learning and Education, edited by P. Tynjälä, M.-L. Stenström, and M. Saarnivaara, 205-222. Dordrecht: Springer Netherlands.

Tynjälä, P., and H. L. T. Heikkinen. 2012. "Beginning Teachers' Transition from Pre-service Education to Working Life: Theoretical Perspectives and Best Practices." Zeitschrift für Erziehungswissenschaft 14 (1): 11-34.

Wang, J., and S. J. Odell. 2007. "An Alternative Conception of Mentor-Novice Relationships: Learning to Teach in Reform-minded Ways as a Context." Teaching and Teacher Education 23 (4): 473-489.

Watts, S. 2014. "User Skills for Qualitative Analysis: Perspective, Interpretation and the Delivery of Impact." Qualitative Research in Psychology 11 (1): 1-14.

Wenger, E. 1998. Communities of Practice: Learning, Meaning, and Identity. Cambridge: Cambridge University Press.

Wilkinson, J., and S. Kemmis. 2015. "Practice Theory: Viewing Leadership as Leading." Educational Philosophy and Theory 47 (4): 342-358.

Yang, C., C. Hu, L. Baranik, and C.-Y. Lin. 2013. "Can Protégés be Successfully Socialized without Socialized Mentors? A Close Look at Mentorship Formality." Journal of Career Development 40 (5): 408-423. 


\section{What is 'good' mentoring? Understanding mentoring practices of teacher induction through case studies of Finland and Australia}

\section{Matti Pennanen, Laurette Bristol, Jane Wilkinson \& Hannu L.T. Heikkinen}

To cite this article: Matti Pennanen, Laurette Bristol, Jane Wilkinson \& Hannu L.T.

Heikkinen (2015): What is 'good' mentoring? Understanding mentoring practices of teacher induction through case studies of Finland and Australia, Pedagogy, Culture \& Society, DOI: 10.1080/14681366.2015.1083045

To link to this article: http://dx.doi.org/10.1080/14681366.2015.1083045

\section{Published online: 11 Sep 2015.}

Submit your article to this journal ๘

山 Article views: 10

Q View related articles 5

View Crossmark data $₫$ 